\section{Developing Evidence-Based Clinical Guidelines For Military Use: Case Study Of Smoking Cessation Guidelines}

\author{
A M Croft, K G Geary, D Irvine, E C Brutus
}

\begin{abstract}
Objective: To develop evidence-based clinical guidelines on smoking cessation, for use throughout the British military.

Method: A ten-member, multiprofessional smoking cessation working group met five times between October 2000 and July 2001 to develop targeted smoking cessation guidelines for use by military health professionals in the clinical setting. The guidelines were based on the best available scientific evidence at that time, mainly systematic review of controlled trials, and individual randomised trials.
\end{abstract}

Results: The agreed military guidelines on smoking cessation were promulgated in July 2001. Three tiers of support were defined. Military health professionals have a key role as nonsmoking models and advocates, and should be trained to use 'brief intervention' at every clinical encounter with a military smoker. 'Intermediate support' (defined as a specialist service delivered by military health professionals who have undergone specific training and continuation training) is to be available at local level. The most heavily addicted military smokers will require referral to civilian smoking cessation clinics. Effective technologies for use at any one of the three levels of care are: nicotine skin patches, nicotine gum, nicotine lozenges and bupropion.

Conclusions: These are the first ever clinical guidelines for military use which meet accepted modern quality criteria. Informal monitoring of the uptake of these guidelines between July 2001 to December 2001 suggests that they have been well received by military health professionals. An audit of their impact on smoking patterns within the UK Armed Forces will commence in 2002. The guidelines will be updated 5-yearly, or sooner.

Keywords: Smoking Cessation, British Military, Evidence-Based Medicine, Clinical Guidelines.

\section{Introduction}

Principles of guideline development

Clinical guidelines have been defined as 'systematically developed statements designed to help practitioners and patients make decisions about appropriate health care for specific circumstances' (1).

Clinical guideline development is a sophisticated science which has achieved prominence in the past decade, partly in reaction to the proliferation of unvalidated and frequently contradictory guidelines which have become a feature of managed healthcare (2). When developed correctly, clinical guidelines can help to translate research findings into health gain (3). Poor guidelines, on the other hand, tend to perpetuate scientific misconceptions and encourage unsafe clinical practice (4).

Guidelines should be based on valid summaries of all the available research evidence relevant to particular clinical questions (5). The scientific content of guidelines should be derived primarily from systematic review of controlled trials, and from individual randomised trials (6).

A clinical guideline development panel should optimally consist of between six to ten members (7). It should include representatives of key disciplines and interest groups $(1,8)$. Panel members need not necessarily have special expertise in the clinical question being addressed, since excessive specialisation within a guidelines panel has been shown to introduce persuasive advocates and other subjectivities, and to act as a source of bias (9-11). The development of any clinical guideline must involve participants who are representative of the envisaged domain of practice (12). For most clinical guidelines, therefore, at least one panel member should be a general practitioner (13).

The language of clinical guidelines should be lucid, and their structure and format should be familiar to the anticipated endusers (14). The judicious use of checklists and key summaries within guidelines has been shown to improve their overall accessibility (15).

Finally, guidelines must be continuously updated to take account of new scientific evidence, particularly the results of new systematic reviews, and of new randomised trials $(16,17)$.

\section{Smoking in the UK military}

Smoking remains the largest single preventable cause of death and disability in the UK (18), and is known to be an important determinant of ill-health in the British Armed Forces (19). British government policy aims to reduce the

Hants, GU11 2LZ. 
prevalence of smoking in the population, in an effort to improve the health of the nation (20-22).

In March 1998 a government-supported initiative led to the publication in Thorax of recommended technologies through which the National Health Service could treat tobacco dependence and reduce the burden of death and ill-health which tobacco causes (23). An updated version of these guidelines was published in Thorax in July 2000, and included 32 specific clinical recommendations, each graded on a scale of ' $A$ ' to ' $C$ ' according to the strength of the primary research evidence underpinning each recommendation (24). These national smoking cessation guidelines are evidencebased, endorsed by the professions, supported by government legally defensible and cost effective.

In October 2000, a smoking cessation working group was established within the UK Ministry of Defence (MOD), to develop military-specific smoking cessation guidelines, for use by military health professionals in the clinical setting. This paper analyses the guideline development process that ensued, and appraises the final product.

\section{Methods}

A ten-member, multi-professional smoking cessation working group met in the Surgeon General's Department five times between October 2000 and July 2001, in order to develop targeted smoking cessation guidelines for use by military health professionals.

The guideline development group included representatives from all three branches of the UK Armed Services, and although it was medically-led, it also had representation from non-medical stakeholders. The group included two general practitioners, a public health physician, an occupational physician, a pharmacist and an environmental health officer. One of the group's members was a civilian (a health and safety officer) and the remainder were military personnel.

The guidelines which gradually evolved were based on the Thorax guidelines of 1998 and 2000, suitably adapted to the military environment. They were further modified by more recent evidence on effective smoking cessation practices which had been published during 2001 in more than twenty systematic reviews in the Cochrane Library (25).

\section{Results}

The agreed military guidelines on smoking cessation were promulgated throughout the British Armed Forces in July 2001, and the smoking cessation working group was then dissolved.

Ten specific evidence-based recommendations were made. These ten recommendations are summarised in Tables 1 and 2. An 'A'-rated recommendation was one which
Table 1: Smoking cessation recommendations for military primary healthcare teams.

1 Primary healthcare teams should ensure that the current smoking status of any military patient is recorded in the medical and dental record. [A]

2 Military GPs should use every opportunity to advise current smokers to stop ('brief intervention'). [A]

3 Military practice nurses should be prepared to encourage known smokers to stop and offer assistance where possible. [C]

4 Military GPs and practice nurses should receive sufficient practical and theoretical training to enable them to deliver opportunistic advice to encourage a cessation attempt, and to offer accurate advice on nicotine replacement therapy (NRT) or bupropion. [A]

5 Other military primary healthcare team professionals should be encouraged to ask about smoking and advise smokers to stop. [C]

See text for explanation of strength of evidence ratings $\mathbf{A}, \mathbf{B}$, and $\mathbf{C}$

Table 2: Recommended technologies for military smokers.

6 Heavy smokers, who are well motivated to stop, should normally be encouraged to use NRT or bupropion. [A]

7 NRT products to be made available to military smokers are the nicotine skin patch, nicotine gum and nicotine lozenges; there is currently no scientific basis for recommending one form of NRT over others. [B]

8 There may be some benefit in combining different forms of NRT, and military prescribers may consider this option for resistant smokers. [B]

9 On account of its adverse effect profile, bupropion should not be prescribed to military smokers as first-line smoking cessation therapy; if so prescribed, personnel using bupropion are to be temporarily downgraded and are unfit to deploy operationally. [B]

10 The most resistant military smokers, who are well motivated to stop, should be referred to a civilian specialist smoking cessation clinic. [A]

See text for explanation of strength of evidence ratings $\mathbf{A}, \mathbf{B}$, and $\mathbf{C}$

was based on many well-designed randomised controlled trials, directly relevant to the recommendation, and yielding a consistent pattern of findings. A 'B'-rated recommendation was based on limited and/or inconsistent evidence from randomised trials. A ' $\mathrm{C}$ '-rated recommendation was one where no evidence was found to exist, but where the issue was considered important enough to merit a specific recommendation, based on non-randomised studies and on expert opinion.

To assist in the effective implementation of the ten recommendations, a three-tier framework for smoking cessation support was defined within the central policy document promulgating the military guidelines. 'Brief intervention' was to be targeted at individual military smokers, and was directed to be used by all health professionals opportunistically and in a manner tailored to the individual smoker's needs. 'Intermediate support', defined as a specialist service delivered by military health professionals with specific training and continuation training, was to be made 
available at local level. At the top of the hierarchy, the most heavily addicted military smokers were to be referred to civilian smoking cessation clinics.

The smoking cessation technologies which were recommended in the 2001 military guidelines for use at any one of the three levels of care were: nicotine skin patches, nicotine gum, nicotine lozenges and bupropion. Other technologies were studied by the working group (these included acupuncture and hypnosis, and drugs such as clonidine, lobeline, silver acetate, anxiolytics and antidepressants), but it was considered that there was insufficient evidence at that time to recommend any of these technologies within the military setting.

\section{Discussion}

We believe that the smoking cessation guidelines which were developed by the MOD between October 2000 to July 2001 are the first clinical guidelines to have been developed, for any military population, which meet accepted modern quality criteria. Military health professionals have an important role as non-smoking models for their patients, and we believe it is fitting that these first-ever evidence-based guidelines for military use should be closely aligned to present government policy (20-22).

Historically, clinical guidelines produced for the military environment have been formulated by one or two individuals working largely in isolation, or else by consensus panels (sometimes termed Delphi panels) of scientific 'experts'. In the civilian sector, both of these approaches to guideline production have been discredited, since they are open to commercial, institutional and other biases, and generally incorporate no research findings other than the skewed subsets of reports of primary research which can be found in the standard bibliographic databases (4). Indeed the latter approach to guideline production has been dismissed, derisively, as the GOBSAT method (Good Old Boys Sitting Around a Table) (26).

The military smoking cessation guidelines we describe in this paper were developed systematically according to well-validated scientific principles, and can be considered a local version of the accepted national recommendations which address this same clinical question $(23,24)$. It has been shown that Dutch general practitioners were more likely to adopt recommendations that were evidence-based than those that were not (27).

Informal monitoring of the uptake of the MOD guidelines between July 2001 and December 2001 in one constituency, the RAF primary healthcare service, suggested that the guidelines had been well received by military health professionals, with no significant problems identified during their use in clinical encounters (LH Elphinstone, personal communication).
It is too early as yet to say if the introduction of these guidelines will have any long-term impact on smoking rates within the UK Armed Forces. A formal audit of military smoking patterns will commence in 2002, and will be overseen centrally by the MOD Occupational Health Committee.

Updating the military smoking cessation guidelines had been timetabled to occur at 5yearly intervals, in order to incorporate new research findings on the effectiveness or otherwise of available smoking cessation technologies. However a recent study of 17 clinical practice guidelines published by the US Agency for Healthcare Research and Quality found that about half the guidelines were completely out of date in 5.8 years (28). It may therefore prove necessary to update the MOD's smoking cessation guidelines sooner than originally planned.

Within two or three years it is anticipated that the smoking cessation guidelines will be made available to military practitioners in electronic format, as part of the Surgeon General's Information Strategy. This will assist in the continuous updating of the guidelines, and will allow the guidelines to be re-formatted as electronic prompts to good clinical practice (29-31)

\section{References}

1. Field MJ. Lohr KN, eds. Guidelines for clinical practice. From development to use. Washington DC: National Academy Press, 1992.

2. Hibble A, Kanka D, Pencheon D, Pooles F. Guidelines in general practice: the new Tower of Babel? BMF 1998; 317: 862-3.

3. Woolf SH, Grol G, Hutchison A, Eccles M, Grimshaw JG. Potential benefits, limitations and harms of clinical guidelines. BMF 1998; 318: 527 30

4. Eccles M, Clapp Z, Grimshaw J, Adams PC, Higgins B, Purves I, et al. North of England evidence based guidelines development project: methods of guideline development. BMF 1996; 312: 760-2.

5. Chalmers I. Evaluating 'payback' on biomedical research. BMF 2000; 321: 566.

6. Egger M, Davey Smith G, Altman DG. Systematic reviews in health care: meta-analysis in context. 2 nd ed. London: BMJ Publications, 2000.

7. Scott M, Marinker ML. Small group work. In: Marinker ML, editor. Medicine, audit and general practice. 1st ed. London: BMJ Publications, 1990.

8. Bond CM, Grimshaw JM. Multidisciplinary guideline development: a case study from community pharmacy. Health Bull (Edinb) 1995; 53: 29-36.

9. Anonymous. Guidelines for doctors in the new world [editorial]. Lancet 1992; 339: 1197-8.

10. Royal College of General Practitioners. The development and implementation of clinical guidelines: report of the Clinical Guidelines Working Group. London: RCGP, 1995.

11. Woolf SH, DiGuiseppi C, Atkins D, Kamerow DB. Developing evidence-based clinical practice guidelines: lessons learned by the US Preventive Services Task Force. Annu Rev Public Health 1996; 17: 511-38.

12. Leape LL, Park RE, Kahan JP. Group judgments of appropriateness: the effect of panel composition. Qual Assur Health Care 1992; 4: 151-5.

13. Lobach DF. A model for adapting clinical guidelines for electronic implementation in primary care. Proc Annu Symp Comput Appl Med Care 1995; 581-5. 
14. Croft AM. The employment of pregnant and breast-feeding servicewomen. $\mathcal{F} \mathrm{R}$ Army Med Corps 1995; 141: 134-41.

15. Haines A, Feder G. Guidance on guidelines. Writing them is easier than making them work. BMF 1992; 305: 785-6.

16. Shekelle P, Ecccles MP. Grimshaw JM, Woolf SH. When should clinical guidelines be updated? $B M \mathcal{F}$ 2001; 323: 155-7.

17. Brownman GP. Development and aftercare of clinical guidelines. $\mathcal{F} A M A$ 2001; 286: 1509-11.

18. Callum C. The smoking epidemic. London: Health Education Authority, 1998

19. Lodge LH. Tri-Service health questionnaire. $\mathcal{F} R$ Army Med Corps 1991; 137: 80-3.

20. Department of Health. Smoking kills: a White Paper on tobacco. London: The Stationery Office, 1999.

21. NHS Executive. The NHS Plan: a plan for investment, a plan for reform. Leeds: NHSE, 2000.

22. Department of Health. National Service Framework for coronary heart disease. London: The Stationery Office, 2000.

23. Raw M, McNeil A, West R. Smoking cessation guidelines for health professionals. A guide to effective smoking cessation interventions for the health care system. Thorax 1998; 53 (Suppl 5): S119.

24. West R, McNeill A, Raw M. Smoking cessation guidelines for health professionals: an update. Thorax 2000; 55: 987-99.
25. Lancaster T, Silagy C, Sowden A, eds. Cochrane tobacco addiction module. In: Cochrane Collaboration. Cochrane Library. Issue 3. Oxford: Update Software, 2001.

26. Grimshaw J, Eccles M, Russell I. Developing clinically valid practice guidelines. $\mathcal{F}$ Eval Clin Pract 1995; 1: 37-48.

27. Grol R, Dalhuijsen J, Thomas S, Veld C, Rutten G, Mokkink H. Attributes of clinical guidelines that influence use of guidelines in general practice: an observational study. BMF 1998; 317: 858-61.

28. Shekelle PG, Ortiz E, Rhodes S, Morton SC, Eccles MP, Grimshaw JM, Woolf SH. Validity of the Agency for Healthcare Research and Quality Clinical Practice Guidelines. FAMA 2001; 286: 1509-11.

29. Ornstein SM, Garr DR, Jenkins RG, Rust PF, Arnon A. Computer-generated physician and patient reminders. Tools to improve population adherence to selected preventive services. $\mathcal{F}$ Fam Pract 1991; 32: 82-90.

30. Litzelman DK, Dittus RS, Miller ME, Tierney WM. Requiring physicians to respond to computerized reminders improves their compliance with preventive care protocols. $\mathcal{F}$ Gen Intern Med 1993; 8: 311-7.

31. Bargery A. New expert system will provide expertise at your elbow. Practice Computing 1994; Summer: $20-2$. 